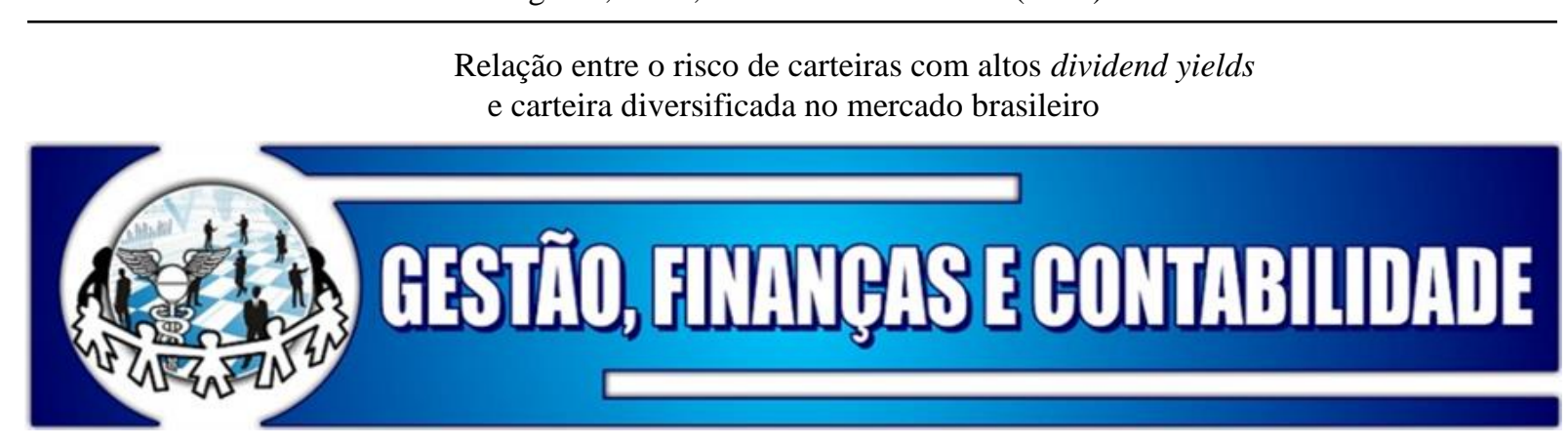

\title{
RELAÇÃO ENTRE O RISCO DE CARTEIRAS COM ALTOS DIVIDEND YIELDS E CARTEIRA DIVERSIFICADA NO MERCADO BRASILEIRO
}

\section{RELATIONSHIP BETWEEN THE RISK OF PORTFOLIOS WITH HIGH DIVIDEND YIELDS AND DIVERSIFIED PORTFOLIO IN THE BRAZILIAN MARKET}

\section{RELACIÓN ENTRE EL RIESGO DE CARTERAS CON ALTA RENTABILIDAD POR DIVIDENDO Y UNA CARTERA DIVERSIFICADA EN EL MERCADO BRASILEÑO}

\begin{abstract}
Vinícius Medeiros Magnani
https://orcid.org/0000-0002-0069-954X

Professor do Departamento de Contabilidade do Centro Univ. Moura Lacerda (CUML) Doutorando do Programa de Pós-graduação em Controladoria e Contabilidade FEA-RP/USP E-mail: vinicius_magnani@hotmail.com

Heloísa Cintra Pollo

https://orcid.org/0000-0002-8252-9172 Bacharel em Ciências Contábeis pelo Centro Universitário Moura Lacerda E-mail: heloisapollo@hotmail.com

Lívia Maria Lopes Stanzani http://orcid.org/0000-0001-8776-879X

Professora do Departamento de Contabilidade da Universidade Paulista (UNIP) Doutoranda do Programa de Pós-graduação em Controladoria e Contabilidade (FEA-RP/USP)

E-mail: $\underline{\text { lmlstanzani@usp.br }}$

Marcelo Augusto Ambrozini https://orcid.org/0000-0003-0933-6064

Professor Livre-Docente da Universidade de São Paulo (FEA-RP/USP) Professor do Programa de Pós-Graduação em Controladoria e Contabilidade (FEA-RP/USP) Doutor em Administração de Organizações (FEA-RP/USP) E-mail: marceloambrozini@usp.br
\end{abstract}

\section{RESUMO}

Com base na Teoria Moderna de Finanças, espera-se que as empresas boas pagadoras de dividendos estejam associadas a um menor risco. Assim, esse trabalho tem como objetivo verificar se os portfólios de ações com altos dividend yields são menos arriscados do que o 
Relação entre o risco de carteiras com altos dividend yields

e carteira diversificada no mercado brasileiro

mercado, no contexto brasileiro. Foram analisados portfólios compostos pelas ações das empresas brasileiras que mais pagaram dividendos durante os anos de 1996 e 2017 e, por meio de testes de média, comparou-se a média do risco apresentado pelas carteiras com alto nível de dividend yield e a média do risco do Ibovespa. Os resultados encontrados sugerem que carteiras com altos dividend yields apresentam risco significativamente maior do que a carteira de mercado, o que contraria a hipótese de pesquisa. Ainda, observou-se que a relação existente entre o risco e o retorno das carteiras com altos dividend yields no Brasil é negativa, demonstrando uma peculiaridade do mercado brasileiro. Assim, o estudo contribui com a literatura ao mostrar que altos rendimentos de dividendos não estão ligados a um risco menor para o investidor, necessariamente, contrariando a relação teórica esperada.

Palavras-chave: dividend yield; risco; retorno.

\section{ABSTRACT}

Based on the Modern Finance Theory, it is expected that good dividend payers will be associated with lower risk, since the uncertainty about the return on investment would be lower. Thus, this paper aims to verify if the portfolios of stocks with high dividend yields are less risky than the portfolio of the stock market, in the Brazilian context. We analyzed portfolios of Brazilian companies' stocks that paid high dividends during 1996 to 2017. Using average tests, we compared the average of the risk presented by portfolios with high level of dividend yield and the average of the Ibovespa risk. The results suggest that portfolios with high dividend yields present a significantly higher risk than the market portfolio, contradicting the research hypothesis. Also, the relationship between the risk and the return presented in portfolios with high dividend yield in Brazil is negative, contradicting the Finance Theory assumptions and showing a peculiarity of the Brazilian market. Thus, the study contributes to the literature by showing that high dividend yields are not linked to lower investor risk, necessarily, contradicting the theory.

Keywords: dividend yield; risk; return.

\section{RESUMEN}

Según la teoría financiera moderna, se espera que las buenas empresas que pagan dividendos estén asociadas con un riesgo menor. Así, este trabajo tiene como objetivo verificar si las carteras de acciones con alta rentabilidad por dividendo son menos riesgosas que el mercado, en el contexto brasileño. Se analizaron las carteras compuestas por empresas brasileñas que pagaron más dividendos durante los años 1996 y 2017 y, mediante pruebas de promedio, se comparó el riesgo promedio que presentan las carteras con una alta rentabilidad por dividendo y el riesgo promedio del Ibovespa. Los resultados sugieren que las carteras con alta rentabilidad por dividendo presentan un riesgo significativamente mayor que la cartera de mercado, contradiciendo la hipótesis de la investigación. Aun así, se observó que la relación entre riesgo y rentabilidad de las carteras con alta rentabilidad por dividendo en Brasil es negativa, lo que demuestra una peculiaridad del mercado brasileño. El estudio contribuye a la literatura al mostrar que los altos rendimientos por dividendos no están vinculados a un menor riesgo para el inversionista, necesariamente, contrario a la relación teórica esperada.

Palavras clave: rentabilidad por dividendo; riesgo; regreso. 


\section{INTRODUÇÃO}

A relação linear existente entre risco e retorno compõe um dos pilares da Moderna Teoria de Finanças. Markowitz (1952) assumiu a premissa de racionalidade do investidor, que maximiza o seu retorno levando em consideração a minimização da variância do seu portfólio. Essa proposta seminal forneceu a base teórica fundamental para diversas aplicações práticas que viriam a ser propostas posteriormente, incluindo a proposição do modelo Capital Asset Pricing Model. A premissa básica do modelo CAPM, relação positiva entre riscos e retornos futuros, fez dele o modelo de apreçamento de ativos mais utilizado no mundo (KECK; LEVENGOOD; LONGFIELD, 1998; GRAHAM; HARVEY, 2001) e, consequentemente, no Brasil (BENETTI; DECOURT; TERRA, 2007; GARRAN, 2006).

Em paralelo, estudos começaram a estudar estratégias de investimento com base no pagamento de dividendos das companhias. Gordon (1963), por exemplo, coloca em xeque o pressuposto da racionalidade dos indivíduos afirmando que, ao se deparar com incertezas futuras em relação à valorização das ações, os investidores avessos ao risco dão preferência ao recebimento de dividendos hoje. Desde então, surgiram vários estudos que buscaram analisar esses pressupostos e as relações de preferências dos investidores (FORTI; PEIXOTO; LIMA, 2015; FONTELES et al., 2012; LOSS; SARLO NETO, 2006; 2003).

No Brasil, os primeiros estudos que buscaram analisar a relação entre o pagamento de dividendos e o retorno de ações iniciaram-se nos anos 2000. No entanto, as pesquisas apresentam resultados dispersos. Bueno (2002), por exemplo, constatou que empresas que ofereceram maiores dividend yields não apresentaram maiores retornos quando comparadas com as demais empresas. Já Neto e Saito (2003) encontraram uma relação positiva entre o retorno de dividendos e o retorno anormal. Entretanto, Freire et al. (2005) mostraram que o dividend yield não foi capaz de explicar o lucro anormal das companhias. Por sua vez, Bernardo e Ikeda (2013) mostraram que empresas que distribuíram maiores dividendos tiveram o risco sistemático reduzido quando comparado ao risco da carteira de mercado. Internacionalmente, essa relação começa a ser estudada por Walter (1956), passa por Black e Scholes (1974), Fama e French (1988) e ainda está em discussão nos trabalhos You, Lin e Hsiao (2010) e Yin e Nye (2021).

Posto isso, visando contribuir com essa literatura, o presente trabalho busca responder a seguinte questão de pesquisa: a estratégia de investimento baseada na formação de portfólios com ações que oferecem altos dividend yields é capaz de oferecer um menor risco quando comparada a uma carteira diversificada de mercado? Dessa forma, o objetivo principal desta pesquisa é verificar se os portfólios de ações com altos dividend yields apresentam menor volatilidade quando comparados a uma carteira diversificada e representativa do mercado acionário brasileiro.

Baseada na teoria apresentada, a hipótese proposta no trabalho foi a de que as carteiras formadas com ações de altos dividend yields apresentam menor risco quando comparadas a uma carteira amplamente diversificada. Sendo assim, o trabalho se propôs a investigar essa relação para um amplo período, iniciando a análise no ano de 1996, a partir da estabilização inflacionária advinda pela implantação do Plano Real, até o final de 2017.

Essa pesquisa possui duas importantes justificativas. A primeira teórica, referindo-se ao teste empírico da relação linear positiva entre o risco e o retorno de investimentos no mercado de ações. Essa relação vem sendo contestada de longa data e este estudo acrescenta constatações que jogam luz ao tema. E a segunda, mais no sentido prático do mercado, direcionada aos 
investidores do mercado acionário, que poderão se valer dos achados aqui apresentados para verificar a eficácia de estratégias conservadoras de investimentos em renda variável.

Após essa introdução, serão apresentados uma revisão das principais pesquisas realizadas sobre este tema (seção 2), o método utilizado nesta pesquisa (seção 3), os resultados obtidos e as principais análises (seção 4) e, na quinta e última seção, serão apresentadas as considerações finais, assim como as limitações desta pesquisa e algumas sugestões para pesquisas futuras.

\section{REVISÃO DA LITERATURA}

Um dos primeiros estudos realizados com o intuito de relacionar o pagamento de dividendos com os retornos das ações das empresas brasileiras foi desenvolvido por Bueno (2002). O autor analisou a relação entre o pagamento de altos dividend yields e as taxas de retornos das ações entre 1994 e 1999. A análise entre os retornos das carteiras foi realizada por meio de testes estatísticos de diferenças de média, além de montar 3 carteiras diferentes para comparar com o Índice Bovespa, carteiras de alto, baixo e zero dividend yield. Os resultados apontaram que a carteira composta com ações de alto nível de dividend yield não foi capaz de superar a taxa de retorno do índice de mercado, enquanto a carteira com zero yield apresentou um retorno de aproximadamente 110 pontos percentuais superiores ao do Ibovespa. Dessa forma, os resultados não forneceram evidências empíricas que suportaram quaisquer estratégias de investimentos com base no yield das ações para o período analisado.

No mesmo ano, De Brito e De Brito (2002) buscaram verificar quais as características do efeito de diversificação de risco no mercado brasileiro, sob o contexto de choques exógenos (crises externas) e endógenos (estabilização do Plano Real) em relação ao mercado. A partir de uma amostra geral de 114 ações, os autores selecionaram as ações mais negociadas em novembro de 1997 e montaram portfólios com 1 até 40 ações - para verificar retornos e riscos no período de 1993 a 1998. Como principais resultados, os autores encontraram que o choque endógeno do processo de estabilização reduziu os níveis absolutos de risco do mercado acionário brasileiro em 1995 e 1996. Já os choques exógenos das crises do México, da Ásia e da Rússia elevaram o nível de percentual médio de risco não diversificável das ações do mercado acionário brasileiro em 1995, 1997 e 1998, respectivamente. Portanto, os choques exógenos resultaram em elevação dos níveis percentuais de risco não diversificável em um primeiro estágio, e aumentou, em um segundo estágio, os níveis absolutos de risco.

Neto e Saito (2003) buscaram analisar o comportamento dos preços das ações após o anúncio do pagamento de dividendos. O estudo foi feito por meio de uma amostra de 163 eventos, que incluía as ações mais negociadas da [B] $]^{3}$, entre 1998 e 2000 . A metodologia escolhida foi a de estudo de evento e foi utilizado o dividend yield para calcular os dividendos distribuídos pelas companhias e o modelo de fator único para o cálculo dos retornos esperados. Foi aplicada uma regressão linear entre os retornos diários de uma ação, considerando as cotações de seu fechamento e a variação diária do Ibovespa. A partir dos resultados obtidos, os autores encontraram uma relação direta entre o dividend yield e o retorno anormal, permitindoos concluir que, quanto maior o dividend yield, maior o retorno anormal acumulado da ação. Outra constatação foi a de que as empresas que pagaram dividendos superiores ao mínimo obrigatório tiveram retornos acumulados maiores. Por sua vez, as empresas que tiveram prejuízo e distribuíram dividendos apresentaram retornos anormais acumulados inferiores às demais. 
Posteriormente, Freire et al. (2005) buscaram evidências empíricas entre o comportamento dos dividendos e os lucros anormais de empresas listadas na $[\mathrm{B}]^{3}$. Com um banco de dados composto por 67 empresas entre os anos de 1996 a 2001, os autores verificaram que a variável explicativa dividend yield apresentou baixo poder explicativo para o lucro anormal das empresas. Dessa forma, os resultados não forneceram indícios de que empresas que pagam mais dividendos apresentam maiores lucros anormais, diferentemente dos resultados de Neto e Saito (2003).

Loss e Sarlo Neto (2006) estudaram se empresas de capital aberto alteram as suas políticas de dividendos frente às necessidades de investimentos permanentes em ativos. $\mathrm{O}$ trabalho utilizou uma base de dados com empresas que comercializaram ações entre 1998 a 2002 na $[\mathrm{B}]^{3}$ e a metodologia implementada foi a de dados em painel. Os resultados dos modelos estimados apontaram que as alterações nas políticas de dividendos não impactam os investimentos permanentes realizados pelas companhias, levando os autores a concluírem que a administração das companhias brasileiras distribuiu dividendos com o objetivo de atender apenas aos aspectos legais, retendo boa parte dos lucros gerados.

Júnior et al. (2010) buscaram verificar, de forma mais abrangente, quais foram os fatores determinantes das políticas de dividendos das firmas brasileiras listadas na Bovespa. O estudo foi realizado pela metodologia de dados em painel, tendo como variáveis dependentes o índice de payout e o dividend yield, e como variáveis explicativas a estabilidade dos dividendos, instabilidade das receitas, oportunidades de crescimento, tamanho, índice de liquidez corrente e alavancagem financeira. O principal resultado elencado pelo estudo foi que as evidências apontaram apoio à escola da relevância dos dividendos, alinhados à teoria de Lintner (1962) e à teoria da agência. Sendo assim, firmas com maiores oportunidades de crescimento tendem a pagar menos dividendos, e quanto maior for o tamanho da firma, maior é a taxa do pagamento de dividendos.

Como conseguinte, Bernardo e Ikeda (2013) investigaram o risco sistemático das carteiras de ações de empresas que oferecem os maiores retornos financeiros aos investidores por meio da distribuição de dividendos e do pagamento de juros sobre capital próprio. Para tanto, os autores avaliaram o risco da carteira formada por ações das empresas com maior dividend yield e compararam com a carteira de mercado. Como metodologia, os autores criaram uma carteira hipotética na proporção da carteira do índice de dividendos (IDIV) da [B] ${ }^{3}$, com ações de maiores dividend yields nos 24 meses anteriores à seleção da carteira, compreendendo o período de janeiro de 2006 - criação do IDIV - a junho de 2011. Os resultados encontrados apontaram que empresas que distribuíram altos dividendos tiveram o risco sistemático reduzido quando comparado ao risco da carteira de mercado.

Para enriquecer as observações, diante do cenário de busca pela satisfação das expectativas individuais em relação ao risco e retorno dos investimentos, Marinho et al. (2013) verificaram em quais indicadores contábeis-financeiros os investidores se baseiam para a tomada de decisão ao elaborar uma carteira de ações. Por meio de questionários enviados a investidores, com 20 questões a respeito de características socioeconômicas e de investimentos, os autores obtiveram um total de 169 respostas no ano de 2012. A partir das respostas obtidas, utilizaram os indicadores financeiros mais citados na literatura, tais como lucro líquido, dividend yield, índice lucro por ação, alavancagem financeira e índice beta para verificar se influenciavam na alocação do portfólio dos investidores. Como resultados foram encontrados que os indicadores beta e lucro da companhia foram as variáveis de maior relevância no modelo proposto inicialmente. Ainda, como resultados adicionais, no modelo completo com todas variáveis coletadas é observado a relevância estatística da variável dividend yield. 
Posteriormente, Leite, Bambino e Hein (2016) compararam a relação entre a política de dividendos e o desempenho econômico financeiro de empresas brasileiras e chilenas. Para isso, os autores construíram uma base de dados com 54 empresas brasileiras e 33 chilenas entre os anos de 2009 e 2013. Foi aplicada uma correlação canônica, combinando três grupos de variáveis: política de dividendos, variáveis de controle e variáveis de desempenho econômico financeiro dos dois países. Como principal resultado, os autores constataram que, de maneira geral, a política de dividendos exerceu uma influência negativa sobre o desempenho econômico-financeiro das organizações brasileiras e chilenas, mais significativamente no Brasil. Dessa forma, empresas que pagam mais dividendos se mostraram menos eficientes, economicamente e financeiramente, em relação às que não pagam.

Mais recentemente, Zanon, De Araújo e Nunes (2017) elaboraram um estudo para verificar a influência da distribuição de dividendos sobre o valor das empresas. Os autores construíram uma base de dados com 33 empresas de capital aberto negociadas no novo mercado da $[\mathrm{B}]^{3}$ entre o período de 2000 a 2017. O trabalho utilizou o modelo baseado no trabalho de Silva e Dantas (2015), tendo como variável dependente o índice market-to-book e a distribuição de dividendos como variável independente, mensurada pelo índice de payout. Entretanto, não foram encontradas evidências de que a distribuição de dividendos apresentou relação significante com o valor de mercado das companhias. Como resultados adicionais, ao desconsiderar períodos de prejuízos, foi observada relação positiva entre o valor de mercado das empresas e a distribuição adotada pelas companhias.

No âmbito internacional, a relação estudada pelo trabalho iniciou-se com Walter (1956) quando ele associa a expectativa dos dividendos futuros à propensão ao risco da realização dos mesmos atrelados a um longo período de tempo. Surge assim a premissa de que empresas com crescimento acima do setor ou do mercado, as chamadas "growth stocks", e que pagam baixos níveis de dividendos, possuem expectativas de aumento no valor acionário. Black e Scholes (1974) encontraram que empresas que aumentaram o nível de dividendos tiveram seus valores apreciados, porém, se as expectativas não fossem atingidas em um determinado período de tempo, o efeito crescente seria temporário. Goetzmann e Jorion $(1993,1995)$ também seguiram na mesma linha.

Por outro lado, Fama e French (1988), Hodrick (1992), Grant (1995), Visscher e Filbeck (2003) e You, Lin e Hsiao (2010) encontraram evidências empíricas que sustentam a relação positiva entre o aumento dos dividendos sobre o retorno acionário das companhias. Em contraponto, Filbeck e Visscher (1997) não verificaram esta relação para o mercado acionário da Grã-Bretanha entre março de 1984 e fevereiro de 1994. Recentemente, Yin e Nye (2021) examinaram a mesma relação entre dividendos e retornos das ações na China e encontraram que há capacidade preditiva entre as variáveis, porém, com o lançamento de regra do Dividendo Semirreigatório em 2008, a relação passou a ser não significante.

A partir da revisão de literatura nacional e internacional, foram observados trabalhos que focaram no retorno da estratégia de investimento com base no pagamento de dividendos (BUENO, 2002; FREIRE et al., 2005), porém não analisaram a relação de risco das carteiras. O trabalho de Bernardo e Ikeda (2013) tangencia esse ponto, mas os autores analisaram apenas o efeito da distribuição de dividendos sobre o risco sistemático das companhias. Posto isso, este estudo busca comparar se ao escolher investir em um portfólio de ações com altos índices de dividend yields, o investidor está incorrendo em um menor risco quando comparado ao risco da carteira de mercado. 


\section{MÉTODO DE PESQUISA}

Esta seção apresenta uma descrição do método utilizado nesta pesquisa para atingir o objetivo aqui proposto de verificar se, empiricamente, a estratégia de investimento em ações com altos dividend yields é menos arriscada do que o investimento em uma carteira amplamente diversificada de mercado.

Vale ressaltar que este estudo tem o intuito de analisar uma longa série histórica de dados. Por isso, as análises iniciaram-se no ano de 1996, a partir da estabilização inflacionária advinda pela implantação do Plano Real, e terminaram no ano de 2017. Objetivou-se, também, abranger uma grande quantidade de empresas. Para isso, foram selecionadas todas as ações das empresas de capital aberto na $[\mathrm{B}]^{3} \mathrm{em}$ cada um dos 22 anos da pesquisa, sendo capturados dados de todas as classes de ações de cada uma das empresas brasileiras, exceto as ADR (American Depositary Receipts).

Todos os dados usados neste estudo foram extraídos da base de dados Economática ${ }^{\circledR}$, exceto as cotações do Ibovespa, que foram obtidas por meio de uma série histórica disponibilizada no site do Banco Central. Primeiramente, foram obtidos os retornos percentuais anualizados de cada uma das ações que apresentaram negociações em cada um dos anos de 1996 a 2017. O retorno da ação foi calculado pela variação percentual de cada título no seu respectivo ano (cotação do final do ano subtraída da cotação no início do ano, dividida pela cotação no final do ano).

Posteriormente, foi coletada a proxy de risco já calculada (equivalente ao desvio-padrão dos retornos individuais dos títulos), também por meio da base de dados Economática® ${ }^{\circledR} \mathrm{O}$ último dado coletado no Economática ${ }^{\circledR}$ foi o retorno anual dos dividendos (dividend yield) de cada uma das ações da amostra. $\mathrm{O}$ dividend yield é um indicador que expressa o retorno percentual que o acionista aufere pela posse de uma determinada ação e é obtido pelo valor do dividendo por ação (DPA) dividido pela cotação da ação no final de cada período (neste caso, o final de cada ano).

Por fim, foram coletadas as cotações diárias do Ibovespa no site do Banco Central, sendo calculado, posteriormente, o desvio-padrão anual dessas cotações, a fim de se obter uma medida de risco para essa variável.

Todos esses dados foram então transportados para uma planilha eletrônica do Microsoft Excel® para a montagem das carteiras. Para isso, inicialmente as ações foram ranqueadas em ordem decrescente de dividend yield, em cada um dos anos analisados. Nessa etapa, foram excluídas as empresas que apresentavam informações ausentes, sendo estas substituídas pelas empresas classificadas subsequentemente. Depois, foram montados portfólios com 10, 20 e 30 ações de maiores retornos de dividendos em cada um dos 22 anos deste estudo. O próximo passo foi calcular o dividend yield de cada carteira, a partir da média aritmética simples dos retornos dos dividendos de cada uma das ações daquela carteira.

Usando esse mesmo raciocínio, o retorno de cada portfólio foi mensurado pela média simples dos retornos dos títulos de cada um dos portfólios. Da mesma forma, o risco de cada uma das carteiras foi obtido pela média dos desvios-padrões dos retornos dos títulos que compuseram cada carteira.

Posteriormente, com o objetivo de verificar a intensidade da relação linear entre os riscos das carteiras e os seus respectivos retornos, foram calculados os coeficientes de correlação de produto de momentos de Pearson, cuja expressão de cálculo está expressa na equação 1 (TRIOLA, 2005, p. 382). 


$$
\begin{aligned}
& \text { Relação entre o risco de carteiras com altos dividend yields } \\
& \text { e carteira diversificada no mercado brasileiro } \\
& r=\frac{n \sum x y-\left(\sum x\right)\left(\sum y\right)}{\sqrt{n\left(\sum x^{2}\right)-\left(\sum x\right)^{2}} \sqrt{n\left(\sum y^{2}\right)-\left(\sum y\right)^{2}}}
\end{aligned}
$$

Em que:

$r=$ Representa o coeficiente de correlação linear para uma amostra.

$\mathrm{n}=$ Representa o número de pares de dados presentes.

$\Sigma=$ Representa a soma dos itens indicados

$\sum x y=$ Indica que cada valor de $\mathrm{x}$ deve ser multiplicado por seu valor correspondente de $\mathrm{y}$.

$\sum x=$ Denota a soma de todos os valores de $\mathrm{x}$ somados

$\sum x^{2}=$ Indica que cada valor de $\mathrm{x}$ deve ser elevado ao quadrado e, então,

$\left(\sum x\right)^{2}=$ Indica que os valores de $\mathrm{x}$ devem ser somados e o total, então, elevado ao quadrado.

De acordo com Levine, Berenson e Stephan (2005, p. 117), "os valores para o coeficiente de correlação se estendem de -1 , para uma correlação negativa perfeita, até +1 , para uma correlação positiva perfeita. Quando o coeficiente de correlação for igual a zero, isso indica uma ausência de correlação entre as variáveis". Além disso, as correlações foram interpretadas de acordo com os parâmetros definidos por Cohen (1988), que estabelece uma classificação para os graus de correlação obtidos, sendo que valores menores do que 0,3 representam uma correlação fraca, valores entre 0,3 e 0,5 representam uma correlação moderada e valores acima de 0,5 representam uma correlação forte.

As correlações entre os riscos e os retornos das carteiras de empresas boas pagadoras de dividendos foram calculadas no software Stata ${ }^{\circledR}$ para cada um dos anos deste estudo. Além disso, foi calculada e analisada a estatística descritiva da amostra (média, desvio-padrão, valores mínimo e máximo), que será apresentada no tópico de análise dos resultados. É importante destacar que o desvio-padrão do risco das carteiras foi calculado apenas para demonstrar a volatilidade dessa variável, assim como aplicado para as demais variáveis relacionadas ao retorno das carteiras.

Verificou-se, também, a normalidade das variáveis por meio do teste estatístico de Shapiro-Wilk, observando-se que, a um nível de significância de $1 \%$, nem todas as variáveis apresentaram distribuição normal, em detrimento do tamanho da amostra. Sendo assim, como técnica de robustez, optou-se por realizar testes de médias paramétricos (teste t) e não paramétricos (Mann-Whitney) e confrontar os resultados obtidos. O teste não paramétrico de Mann-Whitney é adequado para situações de ausência de normalidade na distribuição dos dados e nas quais as amostras analisadas sejam independentes, ou seja, não apresentem relação entre si.

Em seguida, por meio de testes estatísticos realizados no software Stata®, comparou-se a média do risco apresentado por cada uma das carteiras com alto nível de dividend yield e a média do risco do Ibovespa (carteira de mercado), com o objetivo de constatar se havia diferença significativa entre as médias das duas variáveis.

A próxima seção apresenta os resultados obtidos a partir dos procedimentos aqui descritos e tece as análises a partir desses resultados. 
Magnani, Pollo, Stanzani e Ambrozini (2020)

Relação entre o risco de carteiras com altos dividend yields e carteira diversificada no mercado brasileiro

\section{RESULTADOS E ANÁLISES}

Nesta seção serão apresentados os principais resultados obtidos nesta pesquisa, além da análise de suas implicações para a literatura ao confrontar o risco das carteiras com altos dividend yields e o risco de mercado (Ibovespa) ao longo de uma extensa série histórica.

Para isso, primeiramente, a Tabela 1 apresenta a composição da amostra, confrontando a média anual de risco, retorno e dividend yield de cada uma das carteiras analisadas, além do risco de mercado (Ibovespa).

Tabela 1 - Composição da amostra

\begin{tabular}{|c|c|c|c|c|c|c|c|c|c|c|}
\hline$\stackrel{\varrho}{\xi}$ & 承 & 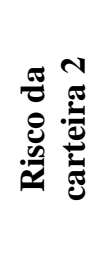 & 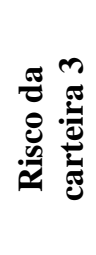 & 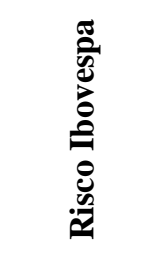 & 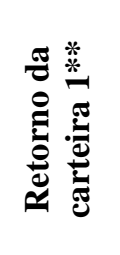 & 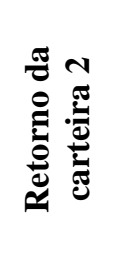 & 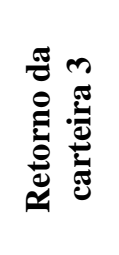 & 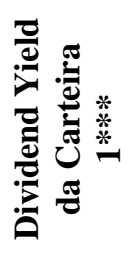 & 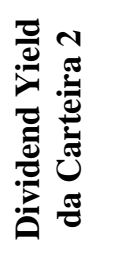 & 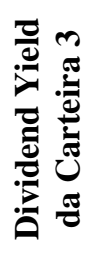 \\
\hline 1996 & 37,06 & 36,23 & 36,41 & $7.147,92$ & 43,13 & 34,22 & 57,07 & 11,76 & 8,30 & 6,63 \\
\hline 1997 & 50,10 & 52,55 & 51,71 & $25.721,83$ & $-7,97$ & 13,22 & 24,65 & 15,17 & 11,49 & 9,55 \\
\hline 1998 & 66,46 & 65,52 & 65,08 & $1.836,00$ & $-15,28$ & $-22,55$ & $-25,65$ & 50,77 & 35,88 & 29,02 \\
\hline 1999 & 61,15 & 59,37 & 57,42 & $2.017,16$ & 158,00 & 170,30 & 157,03 & 10,88 & 8,31 & 7,06 \\
\hline 2000 & 47,20 & 48,26 & 48,23 & $1.329,87$ & 6,90 & 1,62 & 1,55 & 16,61 & 12,56 & 9,90 \\
\hline 2001 & 38,77 & 41,55 & 44,26 & $1.895,84$ & 47,90 & 28,00 & 21,94 & 24,45 & 17,02 & 13,53 \\
\hline 2002 & 42,08 & 41,24 & 40,98 & $1.716,62$ & 29,63 & 22,18 & 20,57 & 19,25 & 14,73 & 12,27 \\
\hline 2003 & 37,54 & 36,24 & 36,13 & $3.275,27$ & 99,30 & 117,43 & 117,92 & 15,25 & 11,61 & 9,67 \\
\hline 2004 & 38,37 & 39,81 & 38,56 & $1.791,72$ & 43,80 & 49,54 & 44,47 & 12,62 & 9,79 & 8,41 \\
\hline 2005 & 34,60 & 36,83 & 36,27 & $2.807,16$ & 0,71 & 9,59 & 7,70 & 15,35 & 12,64 & 10,94 \\
\hline 2006 & 32,52 & 34,33 & 35,60 & $2.435,04$ & 37,52 & 31,87 & 39,22 & 13,36 & 10,42 & 8,79 \\
\hline 2007 & 43,41 & 41,14 & 41,29 & $7.029,29$ & 63,09 & 45,53 & 33,76 & 11,97 & 9,90 & 8,55 \\
\hline 2008 & 68,93 & 61,30 & 61,15 & $11.776,45$ & $-46,57$ & $-34,39$ & $-35,77$ & 20,78 & 16,84 & 14,75 \\
\hline 2009 & 32,33 & 32,89 & 35,03 & $9.909,43$ & 70,10 & 75,07 & 83,29 & 14,80 & 11,79 & 10,01 \\
\hline 2010 & 28,97 & 26,01 & 26,72 & $3.041,28$ & 13,92 & 15,16 & 13,51 & 18,61 & 14,09 & 11,70 \\
\hline 2011 & 31,03 & 28,76 & 30,44 & $5.574,34$ & 17,54 & 11,36 & 0,56 & 13,95 & 11,76 & 10,54 \\
\hline 2012 & 39,08 & 37,27 & 35,12 & $3.930,74$ & $-12,44$ & $-9,07$ & $-2,41$ & 25,64 & 17,47 & 14,04 \\
\hline 2013 & 34,05 & 33,75 & 33,32 & $4.029,15$ & $-13,07$ & $-6,63$ & $-4,85$ & 14,97 & 12,02 & 10,23 \\
\hline 2014 & 42,41 & 39,72 & 38,28 & $3.881,19$ & 5,83 & $-2,61$ & $-8,98$ & 28,10 & 20,80 & 17,52 \\
\hline 2015 & 48,66 & 45,06 & 43,57 & $3.524,64$ & $-41,76$ & $-35,49$ & $-29,75$ & 35,17 & 24,72 & 20,10 \\
\hline 2016 & 42,37 & 41,42 & 40,63 & $7.170,22$ & 43,81 & 39,42 & 43,97 & 13,94 & 10,88 & 9,40 \\
\hline 2017 & 31,78 & 33,22 & 33,12 & $4.892,30$ & 62,30 & 43,93 & 44,11 & 13,48 & 10,03 & 8,56 \\
\hline
\end{tabular}

Legenda: A carteira 1 foi formada com as 10 ações de maior dividend yield naquele ano. A carteira 2 foi formada com as 20 ações de maior dividend yield naquele ano. A carteira 3 foi formada com as 30 ações de maior dividend yield naquele ano.

*O risco foi medido pelo desvio-padrão dos retornos individuais dos títulos que compõem a carteira.

**O retorno da ação foi calculado pela variação percentual de cada título no seu respectivo ano.

***O dividend yield foi obtido pela divisão entre o valor do dividendo por ação (DPA) e a cotação da ação no final de cada ano.

Fonte: Elaborada pelos autores com base nos dados da amostra.

Uma visão geral dos resultados apresentados na Tabela 1 mostra que a expectativa, baseada nos pressupostos teóricos fundamentais de investimentos financeiros, de que carteiras mais arriscadas deveriam oferecer maiores retornos, não se verificou em vários dos 22 anos analisados nesta pesquisa. Para exemplificar, no ano de 1996, a carteira de maior risco (carteira 1) apresentou um retorno (43,13\% no ano) menor que o da carteira $3(57,07 \%$ no ano), de menor risco, contrariando a lógica financeira. 
No ano seguinte (1997), a carteira de maior risco (carteira 2) apresentou um retorno de $13,22 \%$, bem abaixo do retorno da carteira 3 (24,65\%), que apresentou menor risco naquele ano. Esse comportamento contrário à relação positiva entre o risco e o retorno também foi observado nos anos de 1999, 2000, 2001, 2003, 2008, 2010, 2012, 2013 e 2015. Em todos esses anos, as carteiras de maior retorno não foram as mais arriscadas. Em outras palavras, em 11 dos 22 anos analisados, as carteiras de maior risco não foram as que apresentaram os maiores retornos. Cabe ressaltar que o critério adotado para a seleção das ações que compuseram cada um dos portfólios desta pesquisa foi baseado nos maiores dividend yields em cada um dos anos analisados.

Quando analisado o risco dos portfólios em relação ao retorno dos dividendos, uma análise geral da Tabela 1 mostra que, em 14 dos 22 anos analisados, as carteiras mais arriscadas foram aquelas que apresentaram os maiores dividend yields, a saber: 1996, 1998, 1999, 2002, 2003, 2007, 2008, 2010, 2011, 2012, 2013, 2014, 2015, 2016. Esses resultados sugerem indícios de que parte do risco assumido por investimentos em carteiras de maior desvio-padrão de retornos foi compensado pelo maior retorno dos dividendos. Apenas nos anos de 2001, $2006 \mathrm{e}$ 2009 os portfólios de maior dividend yield apresentaram os menores riscos em comparação às demais carteiras.

Assim, os achados empíricos desta pesquisa sugerem indícios de que, na maioria dos anos analisados, a estratégia de se investir em carteiras de ações que oferecem altos retornos de dividendos não reduz o risco incorrido pelo acionista. No entanto, esse risco é recompensado pelo maior retorno obtido pelos investidores. Em outras palavras, quando o investidor adota a estratégia de montar uma carteira de ações formada por empresas cujos dividendos representam um alto retorno ao investidor em relação à cotação do título, essa estratégia não é capaz de garantir uma redução na volatilidade dos preços das ações, mas esse risco é recompensado pelo alto retorno em termos de dividendos.

Com relação à análise dos retornos dos dividendos em comparação à valorização das ações das carteiras, uma análise geral da Tabela 1 mostra que, em 8 dos 22 anos analisados $(1998,2000,2001,2002,2007,2011,2014,2017)$, as carteiras que ofereceram os maiores dividend yields foram também as que apresentaram os maiores retornos percentuais nos preços dos títulos, potencializando os ganhos totais aos investidores. Complementando essas análises, a Tabela 2 apresenta os resultados das estatísticas descritivas para cada uma das variáveis deste estudo.

Tabela 2 - Estatística Descritiva

\begin{tabular}{c|c|c|c|c|c|c}
\hline Variável & Observações & Média & Mediana & $\begin{array}{c}\text { Desvio - } \\
\text { padrão }\end{array}$ & Mínimo & Máximo \\
\hline Risco da Carteira 1 & 22 & 42,22 & 38,92 & 11,12 & 28,96 & 68,92 \\
\hline Risco da Carteira 2 & 22 & 41,47 & 39,76 & 10,29 & 26,01 & 65,51 \\
\hline Risco da Carteira 3 & 22 & 41,33 & 38,42 & 9,88 & 26,71 & 65,07 \\
\hline Ln Risco do Ibovespa & 22 & 8,28 & 8,22 & 0,72 & 7,19 & 10,16 \\
\hline Retorno da Carteira 1 & 22 & 27,56 & 23,58 & 46,94 & $-46,56$ & 158,00 \\
\hline Retorno da Carteira 2 & 22 & 27,16 & 18,66 & 47,49 & $-35,49$ & 170,29 \\
\hline Retorno da Carteira 3 & 22 & 27,45 & 21,25 & 46,49 & $-35,76$ & 157,02 \\
\hline Dividend Yield da Carteira 1 & 22 & 18,94 & 15,21 & 9,34 & 10,88 & 50,77 \\
\hline Dividend Yield da Carteira 2 & 22 & 14,22 & 11,90 & 6,30 & 8,30 & 35,87 \\
\hline Dividend Yield da Carteira 3 & 22 & 11,87 & 10,12 & 5,03 & 6,63 & 29,02 \\
\hline
\end{tabular}

Fonte: Elaborada pelos autores com base nos dados da amostra. 
Nota-se que a mediana e a média das variáveis, na maioria dos casos, apresentam valores próximos entre si, sugerindo que a amostra é homogênea, ou seja, sem valores extremos e altos que poderiam afetar o cálculo da média. Quanto às variáveis relacionadas aos "retornos das carteiras", é possível perceber que as mesmas apresentam média e mediana positivas, sugerindo que, a despeito de existirem valores negativos na amostra (mínimo), há predominância de carteiras com retornos positivos.

As variáveis relacionadas ao "retorno da carteira" foram as únicas que apresentaram um alto desvio-padrão, com este valor superando, inclusive, a própria média das variáveis. Isso sugere uma certa heterogeneidade e variabilidade desses valores ao longo dos anos. O mesmo não ocorre com as demais variáveis: "risco da carteira" e "dividend yield", cujos valores de desvio-padrão são significativamente menores do que a média. A variável "Risco do Ibovespa", por apresentar naturalmente valores muito altos em relação às demais variáveis analisadas, foi logaritmizada, não apresentando, portanto, valores extremos, nem um alto desvio-padrão. Vale ressaltar que o desvio-padrão também foi aplicado para as variáveis de risco como forma de mensurar a volatilidade dessa variável na amostra, apenas para fins comparativos entre as carteiras.

Tabela 3 - Matriz de Correlação

\begin{tabular}{|c|c|c|c|c|c|c|c|c|c|c|}
\hline & 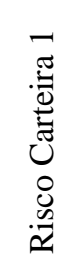 & 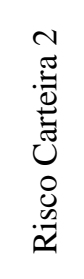 & 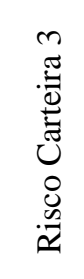 & $\begin{array}{l}\tilde{0} \\
0 \\
0 \\
0 \\
0 \\
0 \\
0 \\
0 \\
0 \\
0\end{array}$ & 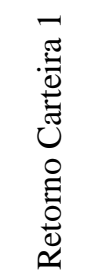 & 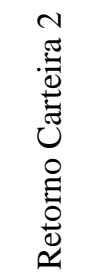 & 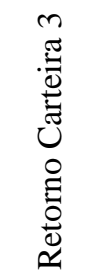 & 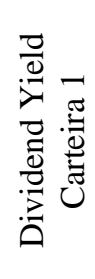 & 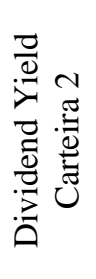 & 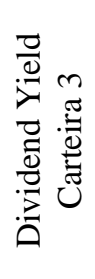 \\
\hline Risco carteira 1 & 1.00 & 0.98 & 0.97 & 0.19 & -0.17 & -0.10 & -0.14 & 0.47 & 0.49 & 0.49 \\
\hline Risco carteira 2 & & 1.00 & 0.99 & 0.20 & -0.12 & -0.06 & -0.09 & 0.46 & 0.46 & 0.46 \\
\hline Risco carteira 3 & & & 1.00 & 0.21 & 0.11 & -0.06 & -0.09 & 0.45 & 0.46 & 0.46 \\
\hline Risco Ibovespa & & & & 1.00 & -0.20 & -0.10 & -0.04 & -0.19 & -0.18 & -0.17 \\
\hline Retorno carteira 1 & & & & & 1.00 & 0.97 & 0.95 & -0.52 & -0.55 & -0.56 \\
\hline Retorno carteira 2 & & & & & & 1.00 & 0.98 & -0.54 & -0.56 & -0.57 \\
\hline Retorno carteira 3 & & & & & & & 1.00 & -0.56 & -0.59 & -0.60 \\
\hline DY carteira 1 & & & & & & & & 1.00 & 0.99 & 0.99 \\
\hline DY carteira 2 & & & & & & & & & 1.00 & 0,99 \\
\hline DY carteira 3 & & & & & & & & & & 1.00 \\
\hline
\end{tabular}

Fonte: Elaborada pelos autores com base nos dados da amostra.

Com relação ao objetivo central desta pesquisa, os dados da Tabela 3 mostram que houve uma relação positiva entre o risco das carteiras e o dividend yield. O coeficiente de correlação de Pearson entre o risco e o retorno dos dividendos foi de 0,47 para o portfólio formado com 10 ações, de 0,46 para a carteira com 20 títulos e de 0,46 para a carteira com 30 ações. É importante ressaltar que, de acordo com os parâmetros de Cohen (1988), os graus de correlação apresentados podem ser interpretados como moderados (entre 0,30 e 0,50). Além disso, esses resultados confirmam os achados apresentados na Tabela 1 (ano a ano) de que, empiricamente, no Brasil, durante o período de 1996 a 2017, investidores que buscaram obter maiores retornos montando carteiras com ações de empresas boas pagadoras de dividendos aumentaram os riscos assumidos, consonante com aquilo que é preconizado pela teoria de investimentos. Entretanto, o resultado positivo dessa correlação (risco x dividend yield) também sugere indícios de que as carteiras que pagam altos rendimentos de dividendos apresentam um maior risco atrelado, contrariando a hipótese de que essas carteiras seriam menos arriscadas. 
Além disso, é possível observar ainda que, no agregado dos 22 anos desta pesquisa, o nível geral de dividend yield apresenta uma relação negativa com o retorno das ações (correlações de $-0,52$ para a carteira $1 ;-0,56$ para a carteira $2 ;-0,60$ para a carteira 3 ), sugerindo que, na prática, em vários anos analisados, ações de empresas que oferecem maiores rendimentos de dividendos apresentam um menor retorno percentual nos preços das ações quando comparada com outras carteiras de quantidade diferentes de títulos, ranqueadas pelos maiores pagamentos de dividendos. De acordo com os parâmetros de Cohen (1988), pode-se considerar que estas variáveis apresentam um grau forte e negativo de correlação entre elas (superiores a 0,50).

Ressalta-se que as correlações entre risco e retorno apresentaram graus baixos (inferiores a 0,30), de acordo com Cohen (1988), levando-se a conclusão de que existe uma correlação negativa, porém fraca, entre as variáveis risco e retorno das carteiras: a correlação entre o risco e o retorno da carteira 1 é de $-0,17$; a correlação entre o risco e o retorno da carteira 2 é de -0,06; e a correlação entre o risco e o retorno da carteira 3 é de -0,09. Ainda assim, apesar da fraca correlação apresentada, o aspecto negativo dessa relação sugere que, historicamente no Brasil, quanto maior o risco das carteiras, menor tende a ser o retorno auferido pelo investidor, contrariando o princípio fundamental de finanças de que o retorno de um portfólio deve ser uma função linear positiva do seu risco.

Antes da análise dos testes de médias, verificou-se, na Tabela 4, a normalidade das variáveis da amostra por meio do teste de Shapiro-Wilk.

Tabela 4 - Teste de normalidade (Shapiro-Wilk).

\begin{tabular}{l|c|c|c}
\multicolumn{1}{c|}{ Variável } & $\mathbf{Z}$ & Prob $>\mathbf{Z}$ & Significância \\
\hline Risco carteira 1 & 2,437 & 0,00743 & $* * *$ \\
\hline Risco carteira 2 & 1,745 & 0,04052 & \\
\hline Risco carteira 3 & 1,929 & 0,02689 & \\
\hline Risco do Ibovespa & 4,357 & 0,00001 & $* * *$ \\
\hline Retorno carteira 1 & 0,561 & 0,28741 & \\
\hline Retorno carteira 2 & 2,220 & 0,01320 & \\
\hline Retorno carteira 3 & 1,721 & 0,04264 & $* * *$ \\
\hline Dividend Yield carteira 1 & 3,837 & 0,00006 & $* * *$ \\
\hline Dividend Yield carteira 2 & 3,651 & 0,00013 & $* * *$ \\
\hline Dividend Yield carteira 3 & 3,516 & 0,00022 & \\
\hline
\end{tabular}

Fonte: Elaborada pelos autores com base nos dados da amostra.

Os resultados apresentados na Tabela 4 mostram que, a um nível de confiança de 99\%, não apresentaram normalidade apenas as variáveis: "risco carteira 1", "risco Ibovespa" e as três variáveis referentes ao nível de "dividend yield" das carteiras. As demais variáveis apresentaram normalidade. Sendo assim, para que os resultados tivessem maior robustez, optou-se por realizar testes de médias paramétricos (teste t) e não paramétricos (MannWhitney), adequados para amostras que apresentam distribuição normal e não normal, respectivamente. Os resultados dos testes encontram-se apresentados na Tabela 5.

Tabela 5 - Testes de médias: paramétricos e não paramétricos.

\begin{tabular}{c|c|c|c|c|c}
\hline \multirow{2}{*}{ Variáveis } & \multicolumn{3}{|c|}{ Teste t (paramétrico)- $\boldsymbol{p}$ value } & $\begin{array}{c}\text { Teste Mann- } \\
\text { Whitney (não } \\
\text { paramétrico)- } \\
\text { p value }\end{array}$ \\
\hline Risco Carteira 1 & 44,22 & $0,000^{* * *}$ & $0,0001^{* * *}$ & 0,9999 & $0,000^{* * *}$ \\
\hline
\end{tabular}


Relação entre o risco de carteiras com altos dividend yields e carteira diversificada no mercado brasileiro

\begin{tabular}{l|c|c|c|c|c} 
Risco Ibovespa & 5306,06 & & & \\
\hline Risco Carteira 2 & & & & & \\
\hline Risco Ibovespa & 51,47 & $0,000 * * *$ & $0,0001 * * *$ & 0,9999 & $0,000^{* * *}$ \\
\hline Risco Carteira 3 & 41,33 & \multirow{2}{*nnnn}{$0,000 * * *$} & $0,0001 * * *$ & 0,9999 & $0,000^{* * *}$ \\
\hline Risco Ibovespa & 5306,06 & & & & 0 \\
\hline
\end{tabular}

Obs: Diff $=($ Risco carteira - Risco Ibovespa $)$

Fonte: Elaborada pelos autores com base nos dados da amostra.

De acordo com a Tabela 5, observa-se que os resultados dos testes foram similares, sendo que a análise da diferença de médias por meio do teste não paramétrico corroborou o resultado obtido pela análise da diferença de médias no teste paramétrico para todas as carteiras analisadas.

Tanto os testes paramétricos quanto os não paramétricos mostraram que existe diferença significativa de médias entre o risco da carteira e o risco do Ibovespa. Ainda, por meio do teste de diferença de médias, nas três situações, é possível observar que o risco das carteiras é significativamente maior do que o risco da carteira de mercado. Estes resultados demonstram que as carteiras com diferentes níveis de pagamento de dividendos, alto, médio e baixo, apresentam maior risco quando comparadas ao risco da carteira de mercado.

Assim, nota-se que os resultados obtidos neste estudo confrontam os achados da pesquisa de Bueno (2002), que buscou relacionar o pagamento de dividend yields com o retorno das ações, embora não tenha feito inferências sobre a relação de risco e retorno das carteiras boas pagadoras de dividendos. Na época, Bueno (2002) constatou não ser possível afirmar que ações com altos dividend yields pudessem apresentar retornos médios substancialmente superiores, nem inferiores, aos de ações de outras categorias. No entanto, o presente artigo traz evidências de que o nível geral de dividend yield exibe uma relação negativa com o retorno das ações, indicando que ações com maiores rendimentos de dividendos, na média, evidenciam um menor retorno percentual nos preços das ações, de acordo com os dados analisados.

Tal observação pode contribuir satisfatoriamente para a tomada de decisão dos investidores, assim como a análise da relevância do dividend yield que, segundo Marinho et. al (2013), é a principal variável utilizada por quem deseja elaborar uma carteira de ações. Desta forma, a atual pesquisa fornece indícios que auxiliam os investidores na consideração de tal variável, mesmo se o risco não for reduzido, pois o pagamento de dividendos é compensado pelo maior retorno obtido.

Investigações sobre o poder dos dividendos na previsão do retorno de ações datam de, pelo menos, meados do século passado, quando Walter (1956) questionou a relação entre dividend yield e os preços das ações ordinárias. De lá pra cá, muitas pesquisas foram realizadas, mas os resultados não são conclusivos. Black e Scholes (1974) e Goetzmann e Jorion (1993, 1995), por exemplo, não acreditavam em uma relação positiva entre rendimentos de dividendos e de ações. Por sua vez, Fama e French (1988), Hodrick (1992) e Grant (1995) encontraram evidências que sustentam uma relação positiva. Filbeck e Visscher (1997) mostraram que a estratégia de investimento baseada em ações de empresas que oferecem altos rendimentos não foi eficaz na Grã-Bretanha entre março de 1984 e fevereiro de 1994. No entanto, esses mesmos autores, Visscher e Filbeck (2003), descobriram que a estratégia de alto rendimento de dividendos funcionou para o Índice Toronto 35 durante os primeiros 10 anos de existência do índice para investidores canadenses, produzindo retornos ajustados ao risco mais elevados. 
Saout (2006) testou a estratégia "Dogs of the Dow" (DoD) no mercado de capitais europeu. Essa estratégia consiste na compra das dez ações com maior rendimento de dividendos da Dow Jones Industrial Average em 31 de dezembro e o rebalanceamento anual. Os resultados indicaram que a estratégia produziu retornos ajustados ao risco mais elevados. You, Lin e Hsiao (2010), por sua vez, analisaram empresas listadas em Taiwan entre 2003 a 2007 e concluíram que o desempenho do investimento em um portfólio de rendimento de dividendos pagos em dinheiro durante o segundo ano provou ser significativamente superior ao dos índices de mercado.

Mais recentemente, Yin e Nye (2021) examinaram a capacidade preditiva dos índices de dividendos sobre os retornos das ações na China. Os resultados mostram que os retornos das ações são preditos positivamente pela razão dividendo-preço no período de 2002 a 2018 . No entanto, esse poder preditivo desapareceu depois que a Comissão Reguladora de Valores Mobiliários da China lançou a Regra do Dividendo Semirreigatório em 2008, e essa diminuição repentina na capacidade preditiva não mostrou sinais de reversão.

O trabalho toma como base a questão de que um portfólio com empresas boas pagadoras de dividendos (alto nível de dividend yields) formam investimentos críveis, com baixa incerteza quanto a sua rentabilidade. Entretanto, a relação encontrada confronta a hipótese inicial do trabalho de que as carteiras com altos dividend yields tendem a apresentar menor risco do que a carteira de mercado. Dessa forma, os resultados obtidos também refutam o trabalho de Bernardo e Ikeda (2013), que constataram uma redução no risco sistemático das carteiras que apresentavam altos dividend yields quando comparadas à carteira de mercado. Ademais, os resultados apontam que o nível geral de dividend yield exibe uma relação negativa com o retorno das ações, indicando que ações com maiores rendimentos de dividendos evidenciam um menor retorno percentual nos preços das ações.

Logo, esse trabalho busca contribuir com a literatura sobre política de dividendos ao trazer evidências de que, no mercado acionário brasileiro, as carteiras com altos dividend yields não estão atreladas a um menor risco, conforme as evidências trazidas pela literatura. Além disso, nota-se que ações de maior risco tendem a apresentar um retorno menor, sugerindo uma relação inversa à que deveria ser encontrada de acordo com um dos princípios básicos de finanças.

\section{CONSIDERAÇÕES FINAIS}

Tendo como embasamento teórico a Teoria Moderna de Finanças, o objetivo desse estudo é verificar se os portfólios de ações que pagam altos rendimentos de dividendos são menos arriscados do que a carteira do mercado acionário no contexto brasileiro. De acordo com a literatura, empresas boas pagadoras de dividendos deveriam estar associadas a um menor risco, já que a incerteza com relação à rentabilidade do investimento seria menor.

Dessa forma, nossa hipótese principal de pesquisa analisa se as carteiras com altos dividend yields tendem a apresentar menor risco do que a carteira de mercado. Foram analisados portfólios compostos pelas ações que apresentaram maior nível de dividend yield entre 1996 e 2017. Por meio de testes de médias, comparou-se o risco associado a esses portfólios com o risco apresentado pela carteira de mercado (Ibovespa) em cada ano observado na amostra.

Os resultados obtidos sugerem que carteiras com altos dividend yields apresentam risco significativamente maior do que a carteira de mercado, contrariando a hipótese inicial. No entanto, há que se ressaltar que a carteira de mercado é composta por uma maior quantidade de ativos, o que contribui significativamente para a redução natural do risco do portfólio dada a 
sua maior diversificação. Ainda, observa-se que, conforme aumenta-se o dividend yield da carteira, o seu risco é aumentado, contrariando a expectativa teórica. Ademais, foi possível inferir que a relação existente entre o risco e o retorno das carteiras com altos dividend yields no Brasil é negativa, ou seja, quanto maior o risco dessas carteiras, menor o retorno, sugerindo uma relação inversa a que deveria ser encontrada de acordo com um dos princípios básicos de finanças.

Os achados dessa pesquisa trazem algumas implicações teóricas e práticas para a literatura em finanças corporativas, mais especificamente para as políticas de dividendos. No campo teórico, o trabalho busca contribuir com a literatura sobre política de dividendos ao trazer evidências de que, no Brasil, as carteiras com altos dividend yields não estão atreladas a um menor risco. Uma das possíveis razões para essa relação pode estar atrelada ao caráter obrigatório dos pagamentos de dividendos imposto pela legislação brasileira. De acordo com a legislação societária brasileira, em casos de omissão de cláusulas específicas relativas aos dividendos no estatuto social ou alteração do mesmo, há uma obrigação de uma distribuição mínima de proventos aos acionistas. Assim, nos casos em que as empresas são obrigadas a pagarem um percentual mínimo estabelecido, a prática de distribuição de dividendos torna-se menos discricionária no mercado brasileiro. Além disso, devemos levar em consideração que o Brasil é um país com mercado de capitais ainda bastante incipiente e com um reduzido número de empresas que optam pela captação de recursos por meio da abertura do seu capital em Bolsa, se comparado a países desenvolvidos, o que pode afetar a liquidez e a relação de risco e retorno dos investimentos.

Adicionalmente, em uma abordagem mais prática, os achados podem auxiliar os investidores no desenvolvimento de sua análise estratégica para investimentos em renda variável, ao mostrar que, no mercado brasileiro, existem evidências de um comportamento atípico observado na relação entre o nível de pagamento de dividendos pelas empresas e o risco atrelado a suas ações. Como sugestões para trabalhos futuros, as pesquisas poderiam avaliar se essa relação é afetada por diversificação setorial. Além disso, seria interessante expandir a análise para outros países com características similares ao Brasil.

\section{REFERÊNCIAS}

BENETTI, C.; DECOURT, R. F.; TERRA, P. R. S. The practice of corporate finance in Brazil and in the USA: comparative survey evidence. In: VII Encontro Brasileiro de Finanças. 2008. Disponível em: http://bibliotecadigital.fgv.br/ocs/index.php/ebf/7EBF/paper/view/1822/0

BERNARDO, H. P.; IKEDA, R. H. O enigma dos dividendos e o risco sistemático. Revista Universo Contábil, v. 9, n. 1, p. 104-120, 2013. Disponível em: https://bu.furb.br/ojs/index.php/universocontabil/article/view/2617/2213

BLACK, F. F.; SCHOLES, M. M. The effects of dividend yield and dividend policy on common stock prices and returns. Journal of financial economics, 1974, v. 1., n.1, p. 1-22, 1974. Disponível em: https://doi.org/10.1016/0304-405X(74)90006-3

BUENO, A. F. Os dividendos como estratégia de investimentos em ações. Revista Contabilidade \& Finanças, v. 13, n. 28, p. 39-55, 2002. Disponível em: https://doi.org/10.1590/S1519-70772002000100003 
Magnani, Pollo, Stanzani e Ambrozini (2020)

Relação entre o risco de carteiras com altos dividend yields e carteira diversificada no mercado brasileiro

COHEN, J. Statistical power analysis for the behavioral sciences. Hillsdale, NJ, Erlbaum. 1988.

DE BRITO, A. A.; DE BRITO, N. R. O. Diversificação de risco e choques exógenos sobre o mercado de capitais brasileiro. Revista de Administração da Universidade de São Paulo, v. 37, n. 1, 2002. Disponível em: http://rausp.usp.br/wp-content/uploads/files/v37n1p19a28.pdf

FAMA, E. F.; FRENCH, K. R. Dividend yields and expected stock returns. Journal of financial economics, v. 22, n.1, p. 3-25, 1988. Disponível em: https://ideas.repec.org/a/eee/jfinec/v22y1988i1p3-25.html

FILBECK, G.; VISSCHER, S. Dividend yield strategies in the British stock market. The European Journal of Finance, v. 3, n. 4, p. 277-289, 1997. Disponível em: https://doi.org/10.1080/135184797337372

FONTELES, I. V. et al. Política de dividendos das empresas participantes do Índice Dividendos da BM\&FBovespa. Contabilidade Vista \& Revista, v. 23, n. 3, p. 173-204, 2012. Disponível em: http://www.redalyc.org/articulo.oa?id=197026238007

FORTI, C. A. B., PEIXOTO, F. M., LIMA, D. Fatores determinantes do pagamento de dividendos no Brasil. Revista Contabilidade \& Finanças, v. 26, n. 68, p. 167-180, 2015. Disponível em: https://www.scielo.br/pdf/rcf/2015nahead/pt_1519-7077-rcf-201512260.pdf

FREIRE, H. V. L. et al. Dividendos e lucros anormais: um estudo nas empresas listadas na Bovespa. Revista Contabilidade \& Finanças, v. 16, n. 39, p. 47-67, 2005. Disponível em: https://doi.org/10.1590/S1519-70772005000300005

GARRAN, F. T. Metodologias em uso no Brasil para a determinação do custo de capital próprio para avaliação de ativos por fluxo de caixa descontado. PhD Thesis. Universidade de São Paulo. 2006. Disponível em: https://www.teses.usp.br/teses/disponiveis/12/12139/tde02022007-132550/publico/Custocapital.pdf

GRAHAM, J. R.; HARVEY, C. R. The theory and practice of corporate finance: Evidence from the field. Journal of financial economics, v. 60, n. 2-3, p. 187-243, 2001. Disponível em: https://doi.org/10.1016/S0304-405X(01)00044-7

GRANT, J. L. A yield effect in common stock returns. Journal of Portfolio Management, v. 21, n. 2, p. 35-40, 1995. Disponível em:

https://www.researchgate.net/profile/James_Grant9/publication/247905775_A_Yield_Effect in_Common_Stock_Returns/links/547e0d270cf2de80e7cc418c/A-Yield-Effect-in-CommonStock-Returns.pdf

GOETZMANN, W. N.; JORION, P. Testing the predictive power of dividend yields. The Journal of Finance, v. 48, n. 2, p. 663-679, 1993. Disponível em:

https://doi.org/10.1111/j.1540-6261.1993.tb04732.x

GOETZMANN, W. N.; JORION, P. A longer look at dividend yields. The Journal of Business, v. 68, n. 4, p. 483-508, 1995. Disponível em: https://www.jstor.org/stable/2353143 
Magnani, Pollo, Stanzani e Ambrozini (2020)

Relação entre o risco de carteiras com altos dividend yields

e carteira diversificada no mercado brasileiro

GORDON, M. J. Optimal investment and financing policy. The Journal of finance, v. 18, n. 2, p. 264-272, 1963. Disponível em: https://www.jstor.org/stable/2977907

HODRICK, R. J. Dividend yields and expected stock returns: Alternative procedures for inference and measurement. The Review of Financial Studies, v. 5, n. 3, p. 357-386, 1992. Disponível em: https://doi.org/10.1093/rfs/5.3.351

JÚNIOR, W. F. et al. Evidências empíricas dos fatores determinantes das políticas de dividendos das firmas listadas na Bovespa. FACEF Pesquisa- Desenvolvimento e Gestão, v. 13, n.2, 2013. Disponível em:

http://periodicos.unifacef.com.br/index.php/facefpesquisa/article/viewFile/241/233

KECK, T.; LEVENGOOD, E.; LONGFIELD, A. L. Using discounted cash flow analysis in an international setting: a survey of issues in modeling the cost of capital. Journal of Applied Corporate Finance, v. 11, n. 3, p. 82-99, 1998. Disponível em:

https://doi.org/10.1111/j.1745-6622.1998.tb00505.x

LEITE, M.; BAMBINO, A. C.; HEIN, N. Relação entre política de dividendos e desempenho econômico financeiro em empresas brasileiras e chilenas. Revista de Gestão, Finanças e Contabilidade, v. 7, n. 1, p. 205-221, 2017. Disponível em:

https://search.proquest.com/docview/1867921390?pq-origsite=gscholar\&fromopenview=true

\section{LEVINE, D. M.; BERENSON, M. L.; STEPHAN, D. Estatística: teoria e aplicações} usando Microsoft Excel português. Ltc, 2005.

LINTNER, J. Dividends, earnings, leverage, stock prices and the supply of capital to corporations. The review of Economics and Statistics, p. 243-269, 1962. Disponível em: https://www.jstor.org/stable/1926397

LOSS, L.; SARLO NETO, A. Política de dividendos, na prática, é importante? Revista Contabilidade \& Finanças, v. 14.SPE, p. 39-53, 2003. Disponível em: https://doi.org/10.1590/S1519-70772003000400008

LOSS, L.; SARLO NETO, A. O inter-relacionamento entre políticas de dividendos e de investimentos: estudo aplicado às companhias brasileiras negociadas na Bovespa. Revista Contabilidade \& Finanças, v. 17, n. 40, p. 52-66, 2006. Disponível em: https://doi.org/10.1590/S1519-70772006000100005

MARINHO, K. B. A. et al. Indicadores Financeiros e Contábeis que Influenciam a Tomada de Decisão do Investidor na Elaboração de uma Carteira de Ações e na Determinação do Nível de Risco. Revista Evidenciação Contábil \& Finanças, v. 1, n. 2, p. 52-68, 2013. Disponível em: https://dialnet.unirioja.es/servlet/articulo?codigo $=4864943$

MARKOWITZ, H. Portfolio selection. The Journal of Finance, 7.1: 77-91, 1952.

NETO, J. A. N.; SAITO, R. Pagamentos de dividendos e persistência de retornos anormais das ações: evidência do mercado brasileiro. Revista de Administração da Universidade de 
São Paulo, v. 38, n. 2, 2003. Disponível em: http://rausp.usp.br/wpcontent/uploads/files/V3802135.pdf

SAOUT, E. Dividend-Yield Strategies in the European Stock Market. Euro-Mediterranean Economics and Finance, p. 127, 2006.

SILVA, A. O.; DANTAS, J. A. Impacto da política de dividendos no valor de mercado das instituições financeiras no Brasil. Revista de Gestão, Finanças e Contabilidade, v. 5, n. 4, p. 43-63, 2015. Disponível em: http://atena.org.br/revista/ojs-2.2.3-

08/index.php/RGFC/article/view/2579

TRIOLA, M. F. Introdução à estatística. Rio de Janeiro: LTC, 2005.

VISSCHER, S.; FILBECK, G. Dividend-yield strategies in the Canadian stock market.

Financial Analysts Journal, v. 59, n. 1, p. 99-106, 2003. Disponível em:

https://doi.org/10.2469/faj.v59.n1.2506

WALTER, J. E. Dividend policies and common stock prices. The Journal of Finance, v. 11, n. 1, p. 29-41, 1956. Disponível em: https://doi.org/10.2307/2976527

YIN, L.; NIE, J. Adjusted dividend-price ratios and stock return predictability: Evidence from China. International Review of Financial Analysis, v. 73, 2021. Disponível em:

https://doi.org/10.1016/j.irfa.2020.101618

YOU, C.-F.; LIN, S.-H.; HSIAO, H.-F. Dividend yield investment strategies in the Taiwan stock market. Investment management and financial innovations, n. 7, Iss. 2 (contin.), p. 189-199, 2010.

ZANON, A. R. M.; DE ARAÚJO, C. G.; NUNES, A. Influência Da Política De Dividendos No Valor De Mercado Das Empresas Brasileiras. Revista de Gestão, Finanças e Contabilidade, v. 7, n. 3, p. 326-339, 2017. Disponível em:

http://www.spell.org.br/documentos/ver/46580/influencia-da-politica-de-dividendos-no-valorde-mercado-das-empresas-brasileiras-- 